\title{
Perception of Nurses Work Environment in Tertiary Care Hospital in Saudi Arabia
}

\author{
Malek Al Moosa ${ }^{1}$, Salwa Eweis Hassanein ${ }^{2}$, Ayman Alnemsi, Amany Ahmed Abdrbo 3, *, \\ Ofelia Minguez ${ }^{1}$, Fatemah Anwar Al Ghadheeb ${ }^{1}$ \\ ${ }^{1}$ Almoosa Specialist Hospital, Alahsa, KSA \\ ${ }^{2}$ Almoosa College of Health Sciences, KSA and Community Department, Faculty of Nursing, Cairo, Egypt \\ ${ }^{3}$ Almoosa College of Health Sciences, KSA and Nursing Administration Department, Faculty of Nursing, Cairo, Egypt
}

\section{Email address:}

aamanyahmed@hotmail.com (A. A. Abdrbo)

${ }^{*}$ Corresponding author

\section{To cite this article:}

Malek Al Moosa, Salwa Eweis Hassanein, Ayman Alnems, Amany Ahmed Abdrbo, Ofelia Minguez, Fatemah Anwar Al Ghadheeb. Perception of Nurses Work Environment in Tertiary Care Hospital in Saudi Arabia. American Journal of Nursing Science.

Vol. 9, No. 1, 2020, pp. 23-29. doi: 10.11648/j.ajns.20200901.14

Received: December 19, 2019; Accepted: January 6, 2020; Published: January 17, 2020

\begin{abstract}
Nursing practice environment excellence is crucial for the enhancement of health care system performance. Nurses need a work environment that makes them use the full expression of their skills and knowledge. The aim of this study was to assess the perception of nurses' work environment in tertiary care hospital in Saudi Arabia. A descriptive cross-sectional correlation research design and a convenient sampling technique was used to recruit 541 bedside nurses and nursing administrators working in the hospital with a response rate of $98.5 \%$. A self-report questionnaire consists of demographic Characteristics and the Nursing Practice Environment scale. The results indicated that the mean score of nurse participants in hospital affairs was 3.0 (SD 0.47), nursing foundation for quality of care was 3.1 (SD 0.45), nurse manager ability, leadership and support of nurse was 2.9 (SD 0.60), staffing and resources adequacy was 2.6 (SD 0.70) while the mean score of collegial nurse-physician relations was 2.9 (SD 0.57). The overall mean score of the Nursing Practice Environment scale was 2.9 (SD 0.47). This study can guide policy makers, administrators, nurse leaders and educators, to identify areas to improve nurses' work environment; which could translate into significant improvement in patient outcomes.
\end{abstract}

Keywords: Nurses, Work Environment, Tertiary Care Hospital

\section{Introduction}

Nursing practice environment excellence is crucial for the enhancement of health care system performance [1]. Nurses need a work environment that makes them use the full expression of their skills and knowledge [2]. Magnetism that developed by the American Nurses Credentialing Centre (ANCC), is the best practice model that work as guidelines for the development of supportive work environments for nurses [3].

There are 14 characteristics that differentiated organizations best able to recruit and retain nurses during the nursing shortages. Magnetism characteristics include: quality of nursing leadership, organizational structure, management style, personnel policies and programs, professional models of care, professional models of care, quality improvement, consultation and resources, autonomy, community and the health care organization, nurses as teachers, image of nursing, interdisciplinary relationships, and professional development. Higher nursing management in hospitals who understand the magnetism characteristics incorporate them into their leadership practices, and lead others to use them which consequently will improve the work environment for better patient care outcomes [4].

Nursing practice environment defined as the "organizational characteristics of a work setting that facilitate or constrain professional nursing practice" (p. 178) [5]. Nurse work environment has many aspects: nurse participation in hospital affairs, nursing foundations for quality of care, nurse manager ability, leadership and support of nurses, staffing 
and resource adequacy, and collegial nurse-physician relations [5].

Improving work environments can improve nurses' outcomes and patient outcomes [6] such as job satisfaction, decrease missed nursing care, and patient's safety [7]; less burnout, higher quality of care, and safer care [8]. In a secondary analysis study among 12,377 nurses working in 353 hospitals, work environment was associated with electronic health record adoption and usability outcomes such as documentation, medication administration, clinical monitoring and decision-making, and coordination of patient care [9]. In another study in Pakistan, significance positive relationship between the nurse perception and patients' satisfaction about practical environment [10].

In two studies in Jordan, among 650 registered nurses [11], and another study among 330 hospital nurses [12], there was a positive association between nursing work environment and their job satisfaction and their intent to stay.

In Saudi Arabia, few studies investigated nurses work environment. In a study investigated the effect of leadership style on nurses' satisfaction among 89 nurses, use of the transformational leadership style significantly was correlated with higher nurses' job satisfaction in intensive care unit [13] Another two studies done to identify nurses' perception of work environment characteristics using the Nursing Practice Environment questionnaire; one study was among 465 nurses [14] and the other study was among 1007 staff nurses found that nurses' perception of the work environment was moderately high.

Focusing on improving nurses work environment in Saudi Arabia will be the bases for converting hospitals to follow the magnetism characteristics. With the continuous advancement and technology and dynamic changes in health care environment, nursing work environment perception variations such as stressful, unfavorable or burdensome in relation to nurse participation in hospital affaires, nursing foundations for quality care, nursing managers' ability, leadership and support of nurses, staffing and resource adequacy and collegial nurse-physician relations need to be assessed and it will be bases and valuable information for future studies to predicts job outcomes such as job satisfaction and turnover intentions and nurse quality of care. Nurse leaders need to identify areas to improve nurses' work environment; which could translate into significant improvement in patient outcomes.

The aim of this study was to assess the perception of nurses' work environment in tertiary care hospital in Saudi Arabia.

\section{Methods}

\section{Research Questions}

1. What are the characteristics of the nurses participating in the study?

2. What are the characteristics of the practice environment as perceived by nurses?

3. What is the relationship of nurses' selected characteristics with their perception of work environment?

\section{Research Design and Setting}

A descriptive cross-sectional correlation research design was used for this study at a tertiary hospital at Saudi Arabia.

Sampling

A convenient sampling technique was used to recruit all bedside nurses and nursing administrators working in the selected setting $(n=541)$. The inclusion criteria for participants included: Staff nurses holding a current nursing license, practicing bedside patient care, can read and write in English, employed in current setting for not less than a year. Response rate was $98.5 \%$.

\section{Instrument}

A self-report questionnaire was adopted and used for collecting data. The questionnaire comprises Two main parts; First part: Demographic Characteristics including nurses' age, gender, nationality, Marital status, highest educational level, nursing category, department unit, position, years of experience, monthly income, daily job duty, number of sleep hours, and language spoken. Second part is "Nursing Practice Environment (NPE) scale. This scale was derived from Perceived Environment Scale-Nursing Work Index (PESNWI) [5]. It was developed to measure the hospital nursing practice environment. PES-NWI was valid and reliable tool for the measurement of the hospital nursing practice environment [5] with (Cronbach's alpha of the total scale = 0.948). The scale was from (1) strongly agree to (5) strongly disagree. The scale consists 5 subscale/category; (1) Nurse Participation in hospital affaires; (2) nursing foundations for quality care, (3) nursing managers' ability; leadership and support of nurses, (4) staffing and resource adequacy, and (5) collegial nurse-physician relations.

Data Collection Procedure

Survey questionnaires was online administrated to nurses who fit with the inclusion criteria. The survey includes the purpose of study and informed participants that they could choose to withdraw from the study at any time without consequences, with maintain the confidentiality of the participant's identities through the data collection process.

\section{Ethical Considerations}

The researcher obtained approval from the Institutional Review Board (IRB) prior to data collection. Participants were ensured that no personal information would be revealed. No names would be mentioned in any report.

Data Analysis

The data analyses were performed using Statistical Packages for Software Sciences (SPSS) version 21. Descriptive statistics had been presented as counts, proportion (\%) and mean \pm standard deviation. The comparison between PES-NWI and the socio demographic variables were conducted using Mann Whitney $U$ test and Kruskal Wallis test. $\mathrm{P} \leq 0.05$ were considered statistically significant. Correlation procedure were also conducted using Pearson correlation. Normality test were accomplished using Shapiro-Wilk test as well Kolmogorov and Smirnov test, pvalue $\leq 0.05$ were considered as non-parametric test. 


\section{Results}

A total of 541 Nurses were participated in this study. Table 1 presented the socio demographic characteristics of participants. Of the 541 participants, $85 \%$ were females and $15 \%$ were males. About a half of them were in the younger age group (20-30 years old) and nearly all were comprised of non-Saudis $(94.5 \%)$. More than a half of them were married (52.3\%) followed by single with $45.3 \%$. A high proportion of participants were bachelor's degree $(73.8 \%)$ with majority of them had midlevel experience $(40.3 \%)$ and senior nurse (36\%). Many nurses are working in the medicine unit $(40.7 \%)$ and critical care unit $(30.7 \%)$. With regards to years of experience, there were $40.5 \%$ of the respondents who were having $6-10$ years of working experience, followed by $32 \%$ of 2-5 years of experience where most of them (86.3\%) had regular 9 and half hours of duty per day while a great proportion of them (67.1\%) indicated about 5-6 hours of sleep per day. Additionally, majority of them speak English as a medium of language while $43.1 \%$ were able to speak both English and Arabic.

The descriptive statistics of nurses' response to PES-NWI has been elaborated at table 2 . It was revealed that the mean score of nurse participants in hospital affairs was 3.0 (SD 0.47) while the average score of nursing foundation for quality of care was 3.1 (SD 0.45 ) whereas the mean score of the domain for nurse manager ability, leadership and support of nurse was 2.9 (SD 0.60). Additionally, the mean score of staffing and resources adequacy was 2.6 (SD 0.70) while the mean score of collegial nurse-physician relations was 2.9 (SD 0.57). The overall mean score of PES-NWI was 2.9 (SD $0.47)$.

We used Pearson correlation to measure the correlation between each domain of PES-NWI. Based on the results, nurse participation in hospital affairs, nursing foundation for quality of care, nurse manager ability, leadership and support of nurses, staffing and resources adequacy, collegial nursephysician relations and PES-NWI total score were all significantly correlated with each other $(\mathrm{p}-<0.001)$ (Table 3$)$.

When comparing the PES-NWI total score against the socio demographic characteristics of participants, we found significant difference on educational level where those with master's degree or above are associated with high agreement to PES-NWI and its domain. Those working with medicine unit are significantly more associated of having agreement to PES-NWI whereas those with few years of working are associated with having high agreement to PES-NWI and its domain. Furthermore, those who are having enough sleep are also associated with higher agreement to PES-NWI and its domain. Other socio demographic variables included in the table found to have no significant association with PES-NWI and its domain (Table 4).

When comparing the PES-NWI domains among age group in years, nursing category and years of experience, it was revealed that significant differences found between years of experience among nurse participation in hospital affairs ( $p$ $<0.001)$, nursing foundation for quality of care (p-0.001), staffing and resources adequacy (p-0.006) and collegial nurse-physician relations ( $\mathrm{p}-0.002)$. However, no statistical evidence found that age group in years and nursing category has significant difference among the 5 domains of PES-NWI (Table 5).

Table 1. Socio Demographic Characteristics of Participants $(n=541)$.

\begin{tabular}{|c|c|}
\hline Study variables & N (\%) \\
\hline \multicolumn{2}{|l|}{ Gender } \\
\hline Male & $81(15.0 \%)$ \\
\hline Female & $460(85.0 \%)$ \\
\hline \multicolumn{2}{|l|}{ Age Group in years } \\
\hline $20-30$ years & $272(50.3 \%)$ \\
\hline $31-40$ years & $204(37.7 \%)$ \\
\hline$>40$ years & $65(12.0 \%)$ \\
\hline \multicolumn{2}{|l|}{ Nationality } \\
\hline Saudi & $30(05.5 \%)$ \\
\hline Non-Saudi & $511(94.5 \%)$ \\
\hline \multicolumn{2}{|l|}{ Marital status } \\
\hline Single & $245(45.3 \%)$ \\
\hline Married & $283(52.3 \%)$ \\
\hline Divorced or widowed & $13(02.4 \%)$ \\
\hline \multicolumn{2}{|l|}{ Educational level } \\
\hline Diploma or lower & $93(17.2 \%)$ \\
\hline College degree & $34(06.3 \%)$ \\
\hline Bachelor's degree & $399(73.8 \%)$ \\
\hline Master's degree or above & $15(02.8 \%)$ \\
\hline \multicolumn{2}{|l|}{ Nursing Category } \\
\hline Fresh graduate & $15(02.8 \%)$ \\
\hline Midlevel experience & $218(40.3 \%)$ \\
\hline Senior nurse & $195(36.0 \%)$ \\
\hline Charge nurse & $113(20.9 \%)$ \\
\hline \multicolumn{2}{|l|}{ Department unit } \\
\hline Critical care unit & $166(30.7 \%)$ \\
\hline Surgical unit & $67(12.4 \%)$ \\
\hline Medical unit & $220(40.7 \%)$ \\
\hline Others & $88(16.3 \%)$ \\
\hline \multicolumn{2}{|l|}{ Years of experience } \\
\hline$<2$ years & $40(07.4 \%)$ \\
\hline $2-5$ years & $173(32.0 \%)$ \\
\hline $6-10$ years & $219(40.5 \%)$ \\
\hline$>10$ years & $109(20.1 \%)$ \\
\hline \multicolumn{2}{|l|}{ Monthly income (SAR) } \\
\hline$<5,000$ & $364(67.3 \%)$ \\
\hline $5,000-10,000$ & $164(30.3 \%)$ \\
\hline$>10,000$ & $13(02.4 \%)$ \\
\hline \multicolumn{2}{|l|}{ Daily job duty } \\
\hline Regular, 9 hours and half hours per day & $467(86.3 \%)$ \\
\hline Regular, 8 hours per day & $74(13.7 \%)$ \\
\hline \multicolumn{2}{|l|}{ Number of sleep hours } \\
\hline$\leq 4$ hours & $68(12.6 \%)$ \\
\hline About $5-6$ hours & $363(67.1 \%)$ \\
\hline About $7-8$ hours & $110(20.3 \%)$ \\
\hline \multicolumn{2}{|l|}{ Language spoken by nurses } \\
\hline English & $296(54.7 \%)$ \\
\hline Arabic & $12(02.2 \%)$ \\
\hline Both & $233(43.1 \%)$ \\
\hline
\end{tabular}

Table 2. Descriptive statistics of Nurses' Responses to PES-NWI ( $n=541)$.

\begin{tabular}{ll}
\hline PES-NWI Domain & Mean \pm SD \\
\hline Nurse participation in hospital affairs & $03.0 \pm 0.47$ \\
Nursing foundation for quality of care & $03.1 \pm 0.45$ \\
Nurse Manager Ability, Leadership, and Support of Nurses & $02.9 \pm 0.60$ \\
Staffing and Resources Adequacy & $02.6 \pm 0.70$ \\
Collegial Nurse - Physician Relations & $02.9 \pm 0.57$ \\
PES-NWI Total Score & $02.9 \pm 0.47$ \\
\hline
\end{tabular}


Table 3. Correlation Between Practice Environment of the Nursing Environment Index (PES-NWI) ( $n=541)$.

\begin{tabular}{|c|c|c|c|c|c|c|}
\hline$\overline{\mathbf{S N}}$ & Domain & I & II & III & IV & $\bar{V}$ \\
\hline I & Nurse participation in hospital affairs & 1 & & & & \\
\hline II & Nursing foundation for quality of care & $0.769 * *$ & 1 & & & \\
\hline III & Nurse Manager Ability, Leadership, and Support of Nurses & $0.721 * *$ & $0.629 * *$ & 1 & & \\
\hline IV & Staffing and Resources Adequacy & $0.618 * *$ & $0.606 * *$ & $0.653 * *$ & 1 & \\
\hline $\mathrm{V}$ & Collegial nurse - physician relations & $0.587 * *$ & $0.615 * *$ & $0.595 * *$ & $0.555^{* *}$ & 1 \\
\hline VI & PES-NWI total score & $0.861 * *$ & $0.839 * *$ & $0.862 * *$ & $0.842 * *$ & $0.797 * *$ \\
\hline
\end{tabular}

** Correlation is significant at the 0.01 level (2-tailed).

Table 4. Comparison between PES-NWI and Socio-demographic Characteristics of Participants $(n=541)$.

\begin{tabular}{|c|c|c|c|}
\hline Factor & Mean \pm SD & F/T test & P-value \\
\hline \multicolumn{4}{|l|}{ Gender $^{a}$} \\
\hline Male & $02.9 \pm 0.47$ & \multirow{2}{*}{$\mathrm{T}=-0.211$} & \multirow{2}{*}{0.778} \\
\hline Female & $02.9 \pm 0.47$ & & \\
\hline \multicolumn{4}{|l|}{ Age Group in years ${ }^{b}$} \\
\hline $20-30$ years & $02.9 \pm 0.48$ & \multirow{3}{*}{$\mathrm{F}=0.690$} & \multirow{3}{*}{0.375} \\
\hline $31-40$ years & $02.9 \pm 0.46$ & & \\
\hline$>40$ years & $02.9 \pm 0.45$ & & \\
\hline \multicolumn{4}{|l|}{ Nationality $^{a}$} \\
\hline Saudi & $02.9 \pm 0.40$ & \multirow{2}{*}{$\mathrm{T}=-0.103$} & \multirow{2}{*}{0.730} \\
\hline Non-Saudi & $02.9 \pm 0.47$ & & \\
\hline \multicolumn{4}{|l|}{ Marital status ${ }^{b}$} \\
\hline Single & $02.9 \pm 0.48$ & \multirow{4}{*}{$\mathrm{F}=1.331$} & \multirow{4}{*}{0.127} \\
\hline Married & $02.9 \pm 0.46$ & & \\
\hline Divorced or widowed & $03.0 \pm 0.48$ & & \\
\hline \multicolumn{2}{|l|}{ Educational level $^{\mathrm{b}}$} & & \\
\hline College degree & $02.8 \pm 0.50$ & \multirow{3}{*}{$\mathrm{F}=4.369$} & \multirow{3}{*}{$0.018 * *$} \\
\hline Bachelor's degree & $02.9 \pm 0.47$ & & \\
\hline Master's degree or above & $03.3 \pm 0.49$ & & \\
\hline \multicolumn{4}{|l|}{ Nursing Category ${ }^{b}$} \\
\hline Fresh graduate & $02.9 \pm 0.25$ & \multirow{4}{*}{$\mathrm{F}=0.674$} & \multirow{4}{*}{0.833} \\
\hline Midlevel experience & $02.9 \pm 0.46$ & & \\
\hline Senior nurse & $02.9 \pm 0.48$ & & \\
\hline Charge nurse & $02.9 \pm 0.49$ & & \\
\hline \multicolumn{4}{|l|}{ Department unit ${ }^{\mathrm{b}}$} \\
\hline Critical care unit & $02.9 \pm 0.43$ & \multirow{4}{*}{$\mathrm{F}=7.167$} & \multirow{4}{*}{$<0.001 * *$} \\
\hline Surgical unit & $02.9 \pm 0.47$ & & \\
\hline Medicine unit & $03.0 \pm 0.48$ & & \\
\hline Others & $02.9 \pm 0.47$ & & \\
\hline \multicolumn{4}{|l|}{ Years of experience ${ }^{b}$} \\
\hline $6-10$ years & $02.8 \pm 0.42$ & $\mathrm{~F}=5.000$ & 0.001 \\
\hline$>10$ years & $02.9 \pm 0.54$ & & \\
\hline Monthly income (SAR) ${ }^{b}$ & & & \\
\hline$<5,000$ & $02.9 \pm 0.46$ & & \\
\hline $5,000-10,000$ & $02.9 \pm 0.47$ & $\mathrm{~F}=1.293$ & 0.053 \\
\hline$>10,000$ & $03.1 \pm 0.72$ & & \\
\hline Daily job duty ${ }^{\text {a }}$ & & & \\
\hline Regular, 9 hours and half hours per day & $02.9 \pm 0.47$ & & \\
\hline Regular, 8 hours per day & $02.9 \pm 0.44$ & $\mathrm{~T}=-1.185$ & 0.207 \\
\hline Number of sleep hours ${ }^{b}$ & & & \\
\hline$\leq 4$ hours & $02.8 \pm 0.56$ & & \\
\hline About $5-6$ hours & $2.9 \pm 0.42$ & $\mathrm{~F}=17.259$ & $<0.001 * *$ \\
\hline About $7-8$ hours & $03.2 \pm 0.49$ & & \\
\hline Language spoken by nurses ${ }^{b}$ & & & \\
\hline English & $02.9 \pm 0.43$ & & \\
\hline Arabic & $02.9 \pm 0.70$ & $\mathrm{~F}=0.681$ & 0.431 \\
\hline Both & $02.9 \pm 0.49$ & & \\
\hline
\end{tabular}

${ }^{\mathrm{a}} \mathrm{P}$-value has been calculated using Mann Whitney U test; ${ }^{\mathrm{b}} \mathrm{P}$-value has been calculated using Kruskal Wallis test. ** Significant at $\mathrm{p} \leq 0.05$ level. 
Table 5. Comparison between PES-NWI Domains among Selected Socio-demographic Characteristics of Participants ( $n=541)$.

\begin{tabular}{|c|c|c|c|c|c|}
\hline Factor & DOM-I & DOM-II & DOM-III & DOM-IV & DOM-V \\
\hline \multicolumn{6}{|l|}{ Age Group in years } \\
\hline $20-30$ years & $02.9 \pm 0.47$ & $03.1 \pm 0.46$ & $02.9 \pm 0.62$ & $02.6 \pm 0.72$ & $02.9 \pm 0.59$ \\
\hline $31-40$ years & $03.0 \pm 0.46$ & $03.1 \pm 0.45$ & $02.9 \pm 0.59$ & $02.6 \pm 0.70$ & $03.0 \pm 0.55$ \\
\hline$>40$ years & $03.1 \pm 0.51$ & $03.1 \pm 0.48$ & $03.1 \pm 0.58$ & $02.7 \pm 0.61$ & $03.0 \pm 0.53$ \\
\hline$P$-value & 0.341 & 0.555 & 0.464 & 0.404 & 0.247 \\
\hline \multicolumn{6}{|l|}{ Nursing Category } \\
\hline Fresh graduate & $02.9 \pm 0.28$ & $03.0 \pm 0.29$ & $03.0 \pm 0.17$ & $02.8 \pm 0.51$ & $02.9 \pm 0.42$ \\
\hline Midlevel experience & $02.9 \pm 0.44$ & $03.1 \pm 0.43$ & $02.9 \pm 0.59$ & $02.6 \pm 0.68$ & $03.0 \pm 0.58$ \\
\hline Senior nurse & $03.1 \pm 0.48$ & $03.1 \pm 0.49$ & $03.0 \pm 0.59$ & $02.7 \pm 0.70$ & $03.0 \pm 0.58$ \\
\hline Charge nurse & $02.9 \pm 0.50$ & $03.1 \pm 0.46$ & $02.9 \pm 0.68$ & $02.5 \pm 0.76$ & $02.9 \pm 0.54$ \\
\hline$P$-value & 0.473 & 0.710 & 0.670 & 0.371 & 0.841 \\
\hline \multicolumn{6}{|l|}{ Years of experience } \\
\hline$<2$ years & $03.1 \pm 0.55$ & $03.2 \pm 0.57$ & $03.1 \pm 0.58$ & $02.8 \pm 0.62$ & $03.2 \pm 0.59$ \\
\hline $2-5$ years & $03.1 \pm 0.45$ & $03.2 \pm 0.43$ & $03.0 \pm 0.59$ & $02.7 \pm 0.71$ & $03.0 \pm 0.57$ \\
\hline $6-10$ years & $02.9 \pm 0.40$ & $02.9 \pm 0.39$ & $02.9 \pm 0.57$ & $02.5 \pm 0.67$ & $02.9 \pm 0.53$ \\
\hline$>10$ years & $03.1 \pm 0.56$ & $03.1 \pm 0.52$ & $03.0 \pm 0.69$ & $02.6 \pm 0.76$ & $03.0 \pm 0.60$ \\
\hline$P$-value & $<0.001 * *$ & $0.001 * *$ & 0.071 & $0.006 * *$ & $0.002 * *$ \\
\hline
\end{tabular}

DOM-I - Nurse participation in hospital affairs; DOM-II - Nursing foundation for quality of care; DOM-III - Nurse Manager Ability, Leadership, and Support of Nurses; DOM-IV - Staffing and Resources Adequacy; DOM-V - Collegial Nurse - Physician Relations.

P-value has been calculated using Kruskal Wallis test.

** Significant at $\mathrm{p} \leq 0.05$ level.

Nurse participation in hospital affairs

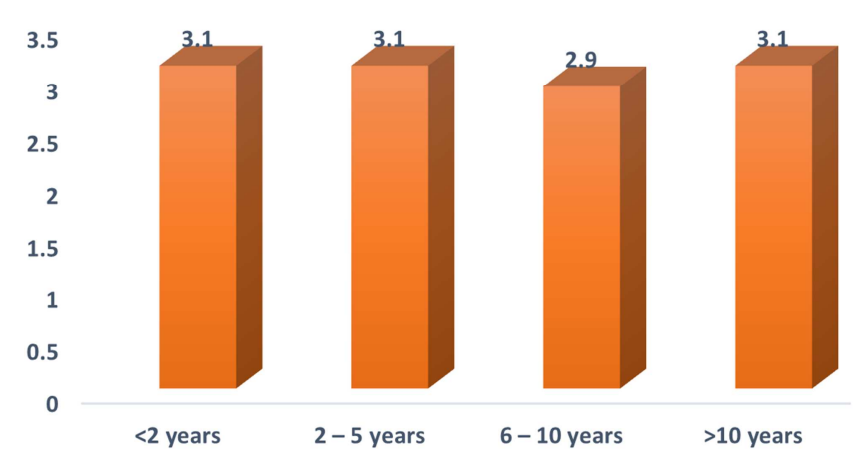

Figure 1. Distribution of Mean Score for Nurse Participation in Hospital Affairs Among Years of Experience.

\section{Nursing foundation for quality of care}

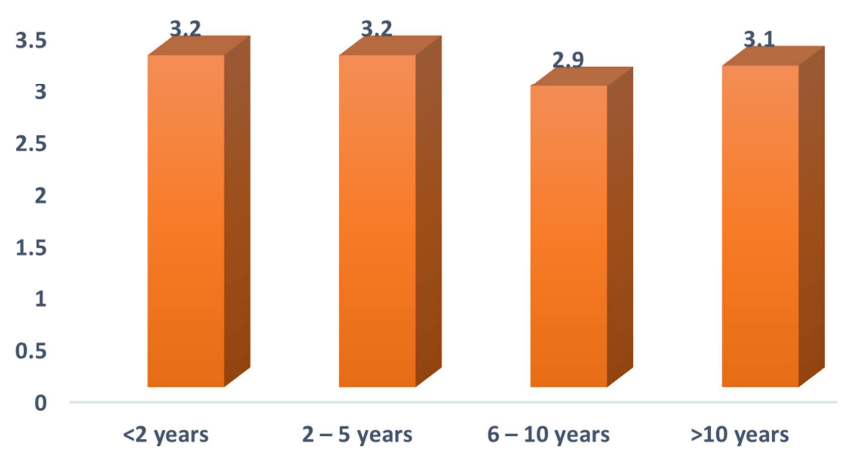

Figure 2. Distribution of mean score for Collegial Nurse - Physician Relations among Years of Experience.
Staffing and Resources Adequacy

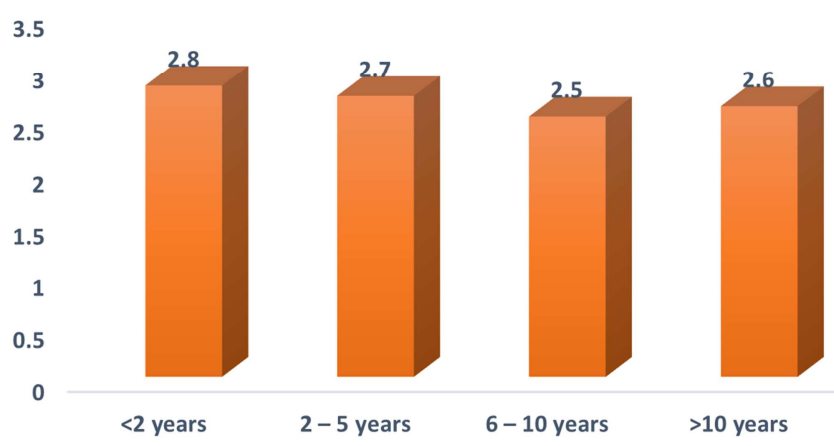

Figure 3. Distribution of mean score for Staffing and Resources Adequacy among Years of Experience.

\section{Collegial Nurse - Physician Relations}

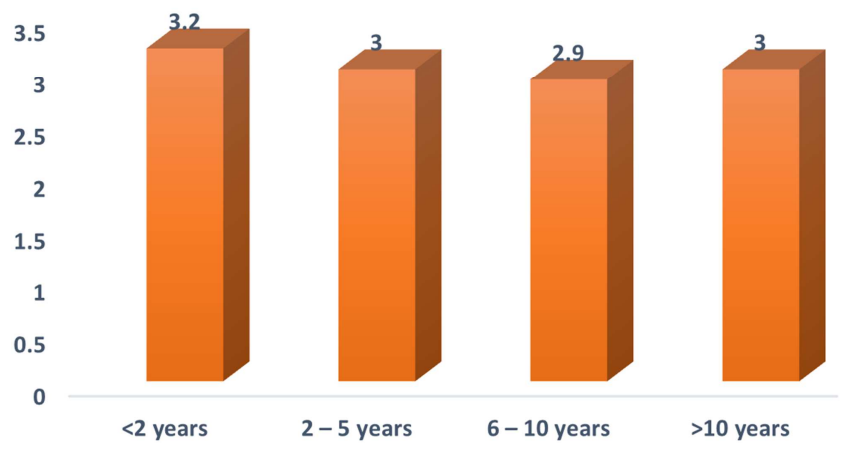

Figure 4. Distribution of mean score for Collegial Nurse - Physician Relations among years of experience. 


\section{Discussion}

The overall total mean score of PES-NWI was moderate $(\mathrm{M}=2.9, \quad \mathrm{SD}=0.47)$, considering that majority of the respondents are staff nurses who routinely work at the bedside with patients, this relatively high mean score suggests favorability of practice environments. This result was in consistence with a Saudi study done by [14] who found a mean score of 2.44 for the total scale of PES-NWI.

Regarding subscale scores, the results indicated a moderate mean score for all subscales which were the same as previous study done among 2004 nurses who rated their hospitals highly in all domains of the practice environment [15] except for the adequate staffing and resources subscale. Across all previous studies, the adequate staffing and resources subscale was most often scored the lowest of the subscales such as this study across all settings [14].

High total mean score of PES-NWI was significantly difference with higher educational level (master's degree), being working in the medical unit and having enough sleep hours and nurses with few years of working. The finding agreed with a study done in mainland China [16] with a total 1223 nurses with a master's or doctoral degree across 115 tertiary hospitals. The research revealed that work environment ratings of nurses were at a moderate level. Medical unit nurses have the highest mean score rating their work environment may be because they represent about $40 \%$ of the sample and the highest response rate from these units. Having enough sleep hours was also expected results that could be interpreted because of wellbeing status that lead to their positive perception of work environment. Nurses with few years of working at the hospital also might have more tolerance and ways of coping with stress in their work.

In this study, significant differences found between years of experience among nurse participation in hospital affairs, nursing foundation for quality of care, staffing and resources adequacy and collegial nurse-physician relations, suggesting that nurses with more years of experience reported higher scores on the PES-NWI. In consistent with these results, previous studies found a statistically differences between organizational attributes and length of working experience in nursing generally, in the hospital setting and in the current position [17]. In addition, nurses' work experience has been reported to influence nurses' perceptions of their work environment [18].

\section{Limitations}

The use of an online survey is one of the limitations of this study; the participants may answer the questions with socially desirable responses. Self-selection to participate in the study may reflect differences between those who participated and those who did not. The findings might be very different with a different approach to recruitment. The sample was limited generalizability to nurses in one hospital, future research should look at other healthcare providers in KSA.

\section{Recommendations for Further Research}

Nursing administrators need to retain nurses with experience since they are active in participation in hospital affairs, participate for quality of care, staffing and resources adequacy and collegial nurse-physician relations. In addition, they need to make sure that nurses have enough sleep hours through wellness programs which will improve nurses' positive perception of their work environment.

Outcomes such as patient satisfaction, nurse-physician communication, empowerment, and nurse-reported patient safety climate need to be tested to explore new relationships to add to the nursing body of knowledge. Future research focused on building and advancing practice theory about the nursing practice environment will be an important contribution to the nursing science. Finally, replication of the study on a wide range of hospitals in Saudi Arabia with larger sample size is needed to increase the validity of the research findings and the generalizability of the results.

\section{Conclusion}

When organizational values align with individual values of nurses, these RNs tend to be more satisfied. This study can guide policy makers, administrators, nurse leaders and educators, to identify areas to improve nurses' work environment; which could translate into significant improvement in patient outcomes. This study calls for the creation of positive practice environments that support excellence, attract and retain nurses, and positively affect both patient outcomes and nurse satisfaction.

\section{References}

[1] Kirksey, Kenn M., Bautista, Loida Indefenso, Chacko, Mary Laly, Kerbow, Katie E., Lincoln, Michelle Clark, MendozaMoore, Monica J., et al., "Enhancing Nurses' Professional Well-Being: The Impact of Clinical Inquiry on Healthy Work Environments," 2019.

[2] Zaccagnini, Mary and Pechacek, Judith M., The doctor of nursing practice essentials: A new model for advanced practice nursing: Jones \& Bartlett Publishers, 2019.

[3] de Brouwer, B. J. M., "Essential elements of an excellent nursing practice environment," 2019.

[4] Thomas, Joan and Herrin, Donna, "Executive master of science in nursing program: incorporating the 14 Forces of Magnetism," JONA: The Journal of Nursing Administration, vol. 38, pp. 64-67, 2008.

[5] Lake, Eileen T., "Development of the practice environment scale of the Nursing Work Index," Research in nursing \& health, vol. 25, pp. 176-188, 2002.

[6] Lake, Eileen T., Sanders, Jordan, Duan, Rui, Riman, Kathryn A., Schoenauer, Kathryn M., and Chen, Yong, "A MetaAnalysis of the associations between the nurse work environment in hospitals and 4 sets of outcomes," Medical care, vol. 57, pp. 353-361, 2019.

[7] dos Reis Dutra, Carla Klava and Guirardello, Edineis de Brito, "Nurse Practice Environment, Job Satisfaction, Safety Climate, and Missed Nursing Care," 2019. 
[8] Liu, Jiali, Zheng, Jing, Liu, Ke, and You, Liming, "Relationship Between Work Environments, Nurse Outcomes, and Quality of Care in ICUs: Mediating Role of Nursing Care Left Undone," Journal of nursing care quality, vol. 34, pp. 250-255, 2019.

[9] Kutney-Lee, Ann, Sloane, Douglas M., Bowles, Kathryn H., Burns, Lawton R., and Aiken, Linda H., "Electronic Health Record Adoption and Nurse Reports of Usability and Quality of Care: The Role of Work Environment," Applied clinical informatics, vol. 10, pp. 129-139, 2019.

[10] Hameed, Sobia and Hussain, M., "Nurses Perception of Practical Environment Relationship with Patient Satisfaction in Government Hospital Lahore," International Journal of Social Sciences and Management, vol. 6, pp. 75-81, 2019.

[11] Al-Hamdan, Z., Manojlovich, M., and Tanima, B., "Jordanian Nursing Work Environments, Intent to Stay, and Job Satisfaction," J Nurs Scholarsh, vol. 49, pp. 103-110, Jan 2017.

[12] AbuAlRub, Raeda, El-Jardali, Fadi, Jamal, Diana, and Abu, N Al-Rub, "Exploring the relationship between work environment, job satisfaction, and intent to stay of Jordanian nurses in underserved areas," Applied nursing research: ANR, vol. 31, pp. 19-23, 2016.

[13] Alshahrani, Fawaz Musaed M. and Baig, Lubna A., "Effect of leadership styles on job satisfaction among critical care nurses in Aseer, Saudi Arabia," Journal of the College of physicians and Surgeons Pakistan, vol. 26, pp. 366-370, 2016.

[14] Almuhsen, Fatimah, Alkorashy, Hanan, Baddar, Fatma, and Qasim, Abdiqani, "Work environment characteristics as perceived by nurses in Saudi Arabia," International Journal of Advanced Nursing Studies, vol. 6, pp. 45-55, 2017.

[15] Stone, L., Arneil, M., Coventry, L., Casey, V., Moss, S., Cavadino, A., et al., "Benchmarking nurse outcomes in Australian Magnet ${ }^{\circledR}$ hospitals: cross-sectional survey," BMC nursing, vol. 18, p. 62, 2019.

[16] Wang, Yi, Zhang, Lixin, Tian, Shuangyue, Wu, Jie, Lu, Jie, Wang, Feifei, et al., "The relationship between work environment and career success among nurses with a master's or doctoral degree: A national cross-sectional study," International Journal of Nursing Practice, p. e12743, 2019.

[17] Hinno, Saima, Partanen, Pirjo, VehvilÄInen-Julkunen, Katri, and Aaviksoo, Ain, "Nurses' perceptions of the organizational attributes of their practice environment in acute care hospitals," Journal of nursing management, vol. 17, pp. 965974, 2009.

[18] Lee, Huan-Fang, Chiang, Hui-Ying, and Kuo, Hui-Ting, "Relationship between authentic leadership and nurses' intent to leave: The mediating role of work environment and burnout," Journal of nursing management, vol. 27, pp. 52-65, 2019. 